\title{
A extensão da expressão veículo automotor para fins de incidência do IPVA $^{1}$
}

\author{
Giovanna Araújo Felix ${ }^{2}$ \\ Maria Luiza Garcia ${ }^{3}$
}

\begin{abstract}
Resumo
O IPVA é um imposto relativamente novo no direito brasileiro, e que representa uma importante fonte de arrecadação dos Estados. A priori, parece ser um imposto simples, mas existem ainda muitos pontos polêmicos a serem debatidos e resolvidos. Entre estes pontos causadores de divergência está o conceito do critério material do IPVA, ou seja, quais os limites da expressão 'veículo automotor'. Algumas Fazendas Estaduais defendem que a o critério material do IPVA, da forma como foi descrito na Constituição Federal abrange embarcações e aeronaves, além dos veículos terrestres. A doutrina e a jurisprudência divergem sobre o tema, o que contribui para a insegurança jurídica dos contribuintes e guerra fiscal entre os Estados. Assim, faz-se necessária a edição de uma lei complementar, de caráter nacional, que defina esta espécie de tributo, e termine com as discussões acerca do tema.
\end{abstract}

Palavras-Chave: IPVA; Veículo Automotor; Critério Material; Embarcações; Aeronaves.

\section{Introdução}

No exercício de sua soberania, o Estado caracteriza-se com um poder superior e que representa uma vontade superior às vontades individuais. Para atingir seus objetivos sociais o Estado precisa de recursos financeiros. É por esse motivo que os Estados têm poder fiscal, isto é, poder de ingressar no patrimônio dos particulares, coercitivamente, cobrando tributos. Portanto, poder fiscal é aquele que permite ao Estado criar e exigir tributos daqueles que estão dentro de seu território, sujeitos a sua soberania territorial.

Importante, entretanto, observar que tributação não é uma relação autoritária do Estado. 0 poder de tributar justifica-se pelos fins do Estado. Os cidadãos elegem através do voto, representantes, que irão elaborar e aprovar regras jurídicas para o Estado. Assim, podemos dizer que por terem outorgado legitimamente poderes aos políticos, os cidadãos

\footnotetext{
${ }^{1}$ Trabalho apresentado como parte integrante da avaliação do 40 bimestre para a Disciplina de Direito Tributário da Universidade Estadual de Londrina.

${ }^{2}$ Acadêmica do 50 ano do Curso de Direito da Universidade Estadual de Londrina.

${ }^{3}$ Acadêmica do 50 ano do Curso de Direito da Universidade Estadual de Londrina.
} 
se obrigam a cumprir as normas previstas no ordenamento jurídico de seu Estado, entre elas, o pagamento dos tributos.

No entanto, o Estado não tem apenas o poder de tributar. Tem também deveres, assim como os contribuintes. As normas a serem aplicadas dizem respeito a ambos, Estado e contribuintes. E é por isso que o direito tributário deve ser seriamente estudado e debatido, para que possa estar sempre a serviço da sociedade, respeitados os princípios constitucionais em sua instituição e aplicação.

Sendo o Brasil uma Federação, o poder tributário é dividido entre a União, os Estados-membros, o Distrito Federal e os Municípios. Ao poder tributário juridicamente delimitado e dividido dá-se o nome de competência tributária, e esta está prevista na Constituição Federal brasileira.

\section{A regra matriz de incidência tributária}

Antes de estudarmos o imposto ora em tela em espécie, faz-se necessário tecer algumas considerações sobre a regra-matriz de incidência fiscal, terminologia esta, adotada por Paulo de Barros Carvalho, como forma de esclarecer e pontuar os aspectos que serão abordados.

A regra matriz de incidência tributária é uma fórmula lógica e abstrata, composta de um antecedente e um conseqüente. 0 antecedente descreve a norma, nele posicionam-se diretrizes para identificação de eventos portadores de expressão econômica. Conforme Carvalho (2007, p. 295), no descritor da norma haverá um critério material (comportamento de alguma pessoa), condicionado no tempo (critério temporal) e no espaço territorial (critério espacial). A proposição lógica conseqüente tem conteúdo prescritor no qual é possível identificar o critério pessoal (os sujeitos ativo e passivo) e um critério quantitativo (a base de cálculo e a alíquota). A conjunção desses dados indicativos fornece ao intérprete da norma tributária a possibilidade de exibir o núcleo lógico-estrutural da norma-padrão, preenchido com os requisitos significativos necessários e suficientes para o impacto jurídico da exação.

O antecedente da norma tributária reflete a hipótese tributária de incidência; 0 conseqüente, por sua vez, revela a relação jurídica tributária. Neste estudo a análise da regra 
matriz restringir-se-á à apreciação do critério material, visto que é sobre este ponto que pairam algumas dificuldades para determinar objetivamente a incidência do IPVA.

\section{Imposto sobre veículos automotores - IPVA}

Os impostos são uma das espécies de tributos previstas em nosso ordenamento, e eles são fontes vitais de financiamento de nossa sociedade. Consoante explanação acima, a competência tributária está delimitada na Carta Magna de 1988; e no que tange à competência tributária dos Estados e Distrito Federal, ela está delimitada no artigo 155. 0 imposto sobre a propriedade de veículos automotores (popularmente conhecido pela sua sigla IPVA) é um imposto de competência dos Estados e do Distrito Federal, que, como 0 próprio nome já diz, incide sobre a propriedade de veículo automotor, e está previsto no artigo 155, inciso III da Constituição Federal.

O IPVA foi instituído em substituição à antiga Taxa Rodoviária Única- TRU, que era cobrada anualmente pela União no licenciamento de veículos. Ainda nos dias de hoje, o IPVA guarda relação com o licenciamento dos veículos, mas deixou de ser taxa para ser imposto, assim como passou a ser competência dos Estados e DF e não mais da União.

Não existe lei complementar que regulamente nacionalmente o IPVA, sendo que cada Estado editou sua própria legislação sobre referido imposto. As alíquotas variam e apresentam, às vezes, feitio extrafiscal, sobretudo quando privilegiam utilitários ou veículos nacionais. Contudo, a ausência de uma lei nacional acerca do tema, gera a malfadada guerra fiscal entre Estados vizinhos, sendo que alguns Estados baixam suas alíquotas a fim de atrair o emplacamento de grandes frotistas em seu território (v.g. Estado do Paraná x Estado São Paulo, com relação a frotas de automóveis destinados a locação).

M uitos são os pontos de conflito, as diferenças e as omissões emergentes dos várias legislações estaduais do IPVA. A edição de uma lei complementar com normas nacionais a respeito dos pontos controvertidos contribuiria para a resolução de tais problemas. Por exemplo, permitiria uma unificação sobre a questão da abrangência ou não das aeronaves e embarcações no conceito de veículo automotor. 


\section{O critério material do IPVA}

De acordo com a regra-matriz de incidência, e com a previsão constitucional do IPVA, afere-se que o critério material do IPVA é "ser proprietário de veículo automotor". Neste contexto, a discussão cinge-se a definir quem a norma entende "ser proprietário" e o que compreende a expressão "veículo automotor".

A partir da ocorrência do fato descrito acima em algum ponto do território nacional, em $1^{\circ}$ de janeiro, em regra (norma geral e abstrata), o Estado (sujeito ativo) passa a ter 0 direito de cobrar o IPVA daquele sujeito passivo.

A dificuldade está em definir precisamente 0 que abrange o conceito de veículo automotor, visto que as legislações estaduais tratam 0 assunto de maneira variada, suscitando demandas judiciais e posições doutrinárias divergentes.

Para regulamentar o IPVA, e em especial o conceito da expressão "veículo automotor" utilizada em seu critério material, seria necessário a edição de uma lei complementar. Não havendo esta lei, muitas questões polêmicas são decididas de maneira diversas em cada Estado-membro, o que fere o princípio da isonomia.

0 conceito de "veiculo automotor" gera muitas controvérsias entre os contribuintes e os Estados, visto que o interesse destes é tributar além dos veículos terrestres, as embarcações e aeronaves motorizadas; enquanto que 0 interesse daqueles é restringir 0 conceito da aludida expressão, a fim de que o imposto incida somente sobre os veículos terrestres.

Segundo Mamede (2002, p. 52), a palavra veículo procede do latim vehiculo, de vehere, que significa transportar por terra ou por mar, por meio de qualquer veículo, a cavalo, em navio, levar às costas. Portanto, veículo é o aparelho ou o instrumento que possui capacidade de transportar pessoas ou coisas, de um local para outro.

A idéia de veículo está ligada à idéia de movimento. Em alguns veículos 0 movimento é gerado por uma força externa que os impulsionam, como o eqüino que puxa a carroça. Outros veículos se "automovimentam", ou seja, são puxados por si mesmos através de um motor e por isso são chamados de veículos automotores.

Conforme Anexo I, do Código de Trânsito Brasileiro veículo automotor é: "Todo veículo a motor de propulsão que circule por seus próprios meios, e que serve normalmente 
para o transporte viário de pessoas e coisas, ou para a tração viária de veículos utilizados para o transporte de pessoas e coisas".

Já o Código Brasileiro de Aeronáutica em seu artigo 106 define aeronave como: "todo aparelho manobrável em vôo, que possa sustentar-se e circular no espaço aéreo, mediante reações aerodinâmicas, apto a transportar pessoas ou coisas".

0 conceito legal do termo embarcação, encontra-se previsto no Decreto №. 87.648/82, também conhecido como Regulamento de Tráfego Marítimo, artigo 10, que dispõe: "significa qualquer construção, capaz de transportar pessoas ou coisas, suscetível de se locomover na água por meios próprios ou não".

Como é possível perceber, a Constituição Federal ao determinar o critério material do IPVA, não foi específica a ponto de incluir as aeronaves e embarcações, ao mesmo tempo em que não as excluiu expressamente.

0 conceito de veículo automotor dado pelo Código de Trânsito Brasileiro não abrange aeronaves, motivo pelo qual elas ficariam fora da incidência do IPVA. E mais, alguns alegam que apesar dos conceitos possuírem pontos em comum, o legislador não as equiparou para fins tributários, inserindo a conotação terrestre ao empregar o "transporte viário" no conceito de veículo automotor.

Contudo, o argumento mais forte, e inclusive apontado diversas vezes nas decisões sobre o tema do Supremo Tribunal Federal (STF), é de que o IPVA é sucessor da antiga TRU, sendo que esta era específica para veículos terrestres, não devendo o IPVA, portanto, ser diferente. A corrente divergente utiliza este argumento em sentido contrário, afirmando que o IPVA deve incidir sobre embarcações e aeronaves justamente porque a TRU foi extinta, e o legislador não especificou que o novo imposto incidiria apenas sobre veículos automotores terrestres porque esta não era sua intenção.

Além disto, podemos ainda dizer que no que se refere à instituição ou majoração de tributos, a interpretação deve ser restrita, e em caso de dúvida, deve-se interpretar a norma da maneira mais favorável ao contribuinte. Sendo assim, deveríamos entender pela não incidência do IPVA sobre aeronaves e embarcações motorizadas.

A lei 14.260/2003, que dispõe sobre o tratamento dado ao IPVA no Estado do Paraná estabelece em seu art. 1ำ, parágrafo único que "para efeito da incidência do imposto, considera-se veículo automotor qualquer veículo terrestre dotado de força motriz própria de 
qualquer tipo, ainda que complementar, destinado ao transporte de pessoas e coisas" (grifo nosso).

Diferentemente, a lei 2877/97, que dispõe sobre o tratamento dado ao IPVA no Estado do Rio de Janeiro, estabelece em seu artigo 1ํ, parágrafo único que "para efeito desta lei, veículo automotor é qualquer veículo aéreo, terrestre, aquático ou anfíbio, dotado de força motriz própria, ainda que complementar ou alternativa de fonte de energia natural".

Em virtude da inexistência de uma lei de caráter nacional, unificando tais conceitos, incumbe às legislações estaduais definir o conceito de veículo automotor sujeito à incidência fiscal do IPVA. Os Estados se amparam no artigo 24, § 30 da Constituição Federal que diz que "inexistindo lei federal sobre normas gerais, os Estados exercerão a competência legislativa plena, para atender as suas peculiaridades". E ainda, no artigo $34, \S 30$ do Ato das Disposições Constitucionais Transitórias, do qual se subtrai que "promulgada a Constituição, a União, os Estados, o Distrito Federal e os Municípios poderão editar as leis necessárias à aplicação do sistema tributário nacional nela previsto".

Ainda, pesa em favor dos que defendem a não incidência do IPVA sobre embarcações e aeronaves o fato destes não se vincularem por nenhum ato registral à célula da partição constitucional da receita deste tributo, que é o município, vez que o banco de dados é de registro nacional. Não existe vínculo do registro nem mesmo perante os Estados, visto que existem capitanias de portos que abrangem mais de uma unidade federada. Já o registro aeronáutico é nacional, sem vinculação a M unicípios, os quais participam da partilha da receita advinda da arrecadação do IPVA.

E mais, mesmo os Estados que adotaram em suas legislações estaduais o conceito amplo de veículos automotores, tais como, Rio de Janeiro e Espírito Santo, não conseguem implementar a cobrança sobre embarcações e aeronaves porque o governo federal não repassa quaisquer informações sobre o banco de dados destes veículos.

Em entendimento diametralmente oposto, Gladston Mamede esclarece que a definição de veículo, e o significado de automotor abrangem todos os veículos que têm movimento intrínseco à estrutura, e que se automovimentam utilizando-se, para tanto, de um motor. Segundo este autor, a Constituição não restringiu a idéia de veículo à movimentação terrestre, o que implica necessariamente a inclusão dos veículos para 
movimentação pela água e pelo ar. A simples presença de motor no veículo aéreo é o suficiente para a tributação (M AM EDE, 2002, p. 23).

\section{A não abrangência das embarcações e aeronaves no conceito de veículo automotor}

Como exemplificado acima, alguns Estados têm defendido a incidência do IPVA sobre embarcações e aeronaves, o que entendemos ser contrário aos princípios Constitucionais.

A lei não pode ensejar dúvidas e o critério material de qualquer tributo deve ser certo, específico e bem definido. No caso, o legislador constituinte apenas pretendeu tributar veículos automotores e caso pretendesse tributar também aeronaves e embarcações deveria ter se manifestado expressamente neste sentido.

Assim, os Estados não têm o direito de tributar outros meios de transporte porque isto violaria vários princípios, como o da segurança jurídica, da legalidade e o da tipicidade tributária.

Do ponto de vista gramatical as embarcações e aeronaves certamente são abrangidas pela expressão veículo automotor porque são meios de transporte motorizados. Mas a interpretação literal/gramatical geralmente é a menos adequada porque deixa de levar em consideração o contexto em que a norma está inserida, e é sempre necessário o exame histórico e teleológico da criação da norma.

Verifica-se que na linguagem usual os automóveis são frequentemente chamados de veículos, enquanto as embarcações são referidas como barcos ou navios e as aeronaves como aviões.

Assim, ao analisar a intenção do constituinte na criação da norma pode-se concluir que pela expressão veículo automotor ele quis compreender apenas carros, motos, caminhões e ônibus.

No que tange à aeronave também cumpre ressalvar que ela não existe para trafegar no Estado ou no município, mas para voar no espaço aéreo, que é da competência da União, e não dos Estados e DF.

Por fim, é mister salientar que a Carta M agna dispõe que compete privativamente à União legislar sobre direito marítimo e aeronáutico (art. 22, I), bem como sobre navegação 
lacustre, fluvial, marítima, aérea e aeroespacial (art. 22, X) e sobre trânsito e transporte (art. $22, \mathrm{XI})$.

\section{Posição da doutrina e da jurisprudência atual}

Por todo o exposto, ousamos discordar do professor Mamede (2002, p.23) quando este afirma que "para o IPVA, a própria licença constitucional referindo-se à propriedade de veículo automotor oferece elementos suficientes para a definição pormenorizada da hipótese de incidência tributária. Não se exige do legislador que liste os tipos de veículos automotores que serão tributados, antecedendo-se à sua criação ou confecção; exige-se apenas que o veículo seja automotor para que seu proprietário tenha o dever de recolher 0 tributo correspondente".

Tal argumento fere completamente o princípio da legalidade, porque apenas a lei pode (e deve) determinar quais veículos serão tributados. $E$ deve determinar exaustivamente, sem deixar que esta competência fique a cargo do poder executivo.

O Egrégio Tribunal de Justiça do Estado do Paraná, a 3ạ Câmara Cível, no processo 0356311-6 proferiu o acórdão n. 28666 em que decidiu por unanimidade pela inadmissibilidade da incidência do IPVA sobre aeronaves. Em brilhante decisão, sustenta que:

A Constituição Federal, ao estabelecer o fato gerador do IPVA, estava se referindo aos veículos de via terrestre, excluindo, portanto, sobre aeronaves. Conclui-se assim, que a cobrança do tributo IPVA incidência sobre aeronaves é ilegal e inconstitucional, restando, portanto o não provimento da apelação. Os autores alegam, também, a aplicação de interpretação alargada do conceito de veículo automotor, todavia a vedação é clara, de acordo com 0 artigo 108, § $1^{\circ}$ do Código Tributário Nacional, que dispõe: 'Art. 108. Na ausência de disposição expressa, a autoridade competente para aplicar a legislação tributária utilizará sucessivamente, na ordem indicada: I - a analogia;(..) § 1 - 0 emprego da analogia não poderá resultar na exigência de tributo não previsto em lei.'. . Assim, é vedada a interpretação analógica para fins de incidência de tributos sem lei expressamente tipificada pretendida pelo Estado do Paraná. Não se pode olvidar que as aeronaves são de competência da União, portanto são registradas na forma prevista na legislação federal, segundo 0 artigo 22, I, CF (...). 0 Supremo Tribunal Federal, no recurso extraordinário n. 134.509-8, decidiu por maioria que a base econômica do IPVA não abrange as embarcações e aeronaves porque considerou que a norma só autoriza a incidência do tributo sobre os veículos de circulação terrestre. Transcrevo abaixo um trecho do voto do ilustre ministro Francisco Rezek: "Os conhecedores do modo nacional de se produzirem textos constitucionais hão de perguntar-se sempre se o constituinte, caso quisesse que o legatário da velha e conhecida Taxa Rodoviária Única se tornasse um imposto capaz de alcançar aviões 
e navios, teria se omitido de fazer referência a embarcações e aeronaves. É claro: se se fizer a análise etimológica da expressão veículos automotores é sempre possível concluir que se pode enquadrar no conceito de veículo automotor o navio e a aeronave. Pode ser enquadrada também qualquer criatura do reino animal, veículo que é porque capaz de transportar coisas e automotor porque depende de qual quer tração externa de sua própria estrutura física. Dos animais mais lentos, na espécie dos moluscos, aos mais velozes; dos mais robustos, como a formiga, que carrega vinte e cinco vezes o seu próprio peso, aos mais frágeis, todos nos incluiríamos no conceito de veículo automotor se ele devesse ser compreendido semanticamente. Já se viu que não é isso. Inúmeras discussões em nosso plenário sobre o que é circulação de mercadorias nos fazem ver que a concepção literal dessa fórmula nos conduziria ao ridículo.

Com relação Ao posicionamento do STF, cabe ainda esclarecer, que atualmente, o Ministro Sepúlveda Pertence, bem como o Ministro Rezek votam pela não incidência do IPVA sobre embarcações e aeronaves; enquanto que o Ministro Marco Aurélio vota em sentido contrário. Contudo, ainda assim, as decisões do STF, apesar de não unâmines quando sobre o tema ora em tela, são no sentido da não-incidência do IPVA sobre embarcações e aeronaves.

\section{Conclusão}

O constituinte não se pronunciou expressamente a respeito da incidência do IPVA sobre embarcações e aeronaves. 0 conceito gramatical de veículo é muito amplo, e literalmente incluiria tudo o que é capaz de realizar transporte, até mesmo animais.

Pela nomenclatura usual, a posição do STF é de que apenas meios de transportes terrestres são chamados de veículos, e acredita-se que o legislador constituinte apenas quis fazer o IPVA incidir sobre estes.

$\mathrm{Na}$ análise do contexto histórico do IPVA, não é razoável concluir que o imposto que veio em substituição à TRU teria a intenção de abarcar meios de transportes aéreos e marítimos.

Não existe lei complementar regulamentando o IPVA e as leis estaduais não podem criar impostos não permitidos pela Constituição, mesmo porque a competência para legislar sobre direito marítimo, aeronáutica, trânsito e transportes é da União. Também é da União a competência para o controle e registro das aeronaves e embarcações. Além disso, as aeronaves são meios de transporte para grandes distâncias, realizando percursos interestaduais e internacionais. 
De outro modo também não é possível a cobrança de tributos sem a existência de lei, por meio de analogia ou resolução, porque isto representaria uma ofensa ao princípio da legalidade e da tipicidade. Não se pode delegar a competência da instituição de tributos ao poder executivo porque tal competência é indelegável.

Conclui-se, por fim, que a abrangência da expressão veículo automotor, contida no IPVA, não abrange as aeronaves e embarcações.

\section{Referências}

CARRAZZA, Roque Antonio. Curso de direito constitucional tributário. 22. ed, São Paulo: Malheiros, 2006.

CARVALHO, Paulo de Barros. Curso de direito tributário. 18. ed. São Paulo: Saraiva, 2007.

FRANCO, Paulo Alves. Código de transito brasileiro anotado. 2. ed. São Paulo: J.H. Mizuno, 2004.

M ACHADO, Hugo de Brito. Curso de direito tributário. 13. ed. rev., atual. e ampl. São Paulo: Editora Malheiros, 1998.

M AMEDE, Gladston. IPVA: imposto sobre a propriedade de veículos automotores; colaboração Eduarda Cotta Mamede. São Paulo: Editora Revista dos Tribunais, 2002.

M ARTINS, Rogério Lindemeyer Vidal Gandra da Silva. O perfil do Imposto sobre a propriedade de veículos automotores: IPVA. In: SILVA, Ives Gandra da (Coord.). Curso de direito tributário. 8. ed. São Paulo: Saraiva, 2001.

M ARTINS, Sérgio Pinto. M anual de Direito tributário. 5. ed. São Paulo: Atlas, 2006.

PAULSEN, Leandro. Direito tributário: Constituição e Código Tributário à luz da doutrina e da jurisprudência/ 9. ed. rev. e atual. Porto alegre: Livraria do Advogado: ESM AFE, 2007.

SILVA, Eduardo Correa da. A não incidência do Imposto sobre Propriedade de Veículos Automotores (IPVA) sobre aeronaves e embarcações. Jus Navigandi, Teresina, v. 9, n. 595, 23 fev. 2005. Disponível em: 〈ttp://jus2.uol.com.br/doutrina/texto.asp?id=6312>. Acesso em: 29 out. 2007. 